\title{
Early moult improves local survival and reduces reproductive output in female pied flycatchers ${ }^{1}$
}

\author{
Judith MORALES², Juan MORENO, Santiago MERINO, Juan J. SANZ \& Gustavo TOMÁS, \\ Departamento de Ecología Evolutiva, Museo Nacional de Ciencias Naturales (CSIC), José Gutiérrez Abascal 2, \\ E-28006 Madrid, Spain, e-mail: judithm@mncn.csic.es \\ Elena ARRIERO, Departamento de Ecología Evolutiva, Museo Nacional de Ciencias Naturales (CSIC), José \\ Gutiérrez Abascal 2, E-28006 Madrid, Spain, and Montana Cooperative Wildlife Research Unit, University \\ of Montana, Missoula, Montana 59812, USA. \\ Elisa LOBATO \& Josué MARTÍNEZ-DE LA PUENTE, Departamento de Ecología Evolutiva, \\ Museo Nacional de Ciencias Naturales (CSIC), José Gutiérrez Abascal 2, E-28006 Madrid, Spain.
}

\begin{abstract}
Overlapping moult and reproduction might be crucial for long-distance migratory birds, which are time-constrained to complete these energy-demanding functions before the onset of migration. However, proximate factors modulating the potential trade-off between moult and breeding, such as haemoparasite infection and stress, have not been studied in wild avian populations. We investigated the occurrence of moult-breeding overlap in females of a Spanish population of pied flycatchers (Ficedula hypoleuca) and its association with female age, haemoparasite prevalences, physiological stress, and condition at initial (incubation phase or beginning of the nestling period) and final breeding stages (days 11-12 of the nestling period). Late-breeding females were more likely to show a moult-breeding overlap than early-breeding females. Female age was not associated with moult status when taking into account laying date and study year. A higher proportion of females infected by Haemoproteus at initial breeding stages showed a moult-breeding overlap. Haemoproteus prevalences at final breeding stages did not differ according to moult status. Females with a moult-breeding overlap also showed better condition and lower stress levels (HSP60 levels) at the end of the season. A higher proportion of moulting females returned to the breeding grounds in the following season compared with non-moulting ones. Conversely, moulting females showed reduced hatching success and numbers of hatchlings and fledglings. Overlapping moult and breeding might be the expression of a shift in resource allocation between present and future reproduction, towards increased self-maintenance and reduced reproductive investment.
\end{abstract}

Keywords: Ficedula hypoleuca, Haemoproteus, HSP, life history trade-offs, local survival, moult-breeding overlap.

Résumé : Un chevauchement temporel de la mue et de la reproduction peut être crucial pour les oiseaux migrateurs de longues distances puisque qu'ils sont restreints dans temps pour compléter ces fonctions énergivores avant le début de la migration. Cependant, des facteurs tels que les infections parasitaires du sang et le niveau de stress pouvant moduler le compromis potentiel entre la mue et la reproduction n'ont pas été étudié dans les populations sauvages d'oiseaux. Nous avons étudié l'existence d'un chevauchement de la mue et de la reproduction chez les femelles d'une population de gobe-mouche noir Ficedula hypoleuca en Espagne et la relation avec l'âge de la femelle, la prévalence de parasites du sang, le stress physiologique et la condition au début de la reproduction (à la phase d'incubation ou juste après l'éclosion) et aux derniers stades de la reproduction (les jours 11-12 de la période d'élevage). Les femelles nichant tardivement avaient plus de chance de présenter un chevauchement de la mue et de la reproduction que celles nichant hâtivement. L'âge de la femelle n'avait pas de lien avec le stade de mue lorsque la date de ponte et l'année d'étude étaient prises en considération. Une plus grande proportion de femelles infectées par Haemoproteus au début de période de reproduction démontraient un chevauchement de la mue et de la reproduction. La prévalence de Haemoproteus aux derniers stades de la reproduction ne différaient pas en fonction du stade de mue. Les femelles dont la mue et le reproduction se chevauchaient étaient aussi en meilleure condition et avaient des niveaux de stress (HSP60) moins élevés à la fin de la saison. Une plus grande proportion de femelles ayant mué sont retournées aux sites de reproduction la saison suivante en comparaison avec celles n'ayant pas mué. À l'opposé, les femelles en mue avaient un plus faible succès d'éclosion et moins d'oisillons à l'éclosion et à l'envol. Ainsi, le chevauchement de la mue et de la reproduction peut être l'expression d'un transfert dans l'allocation des ressources entre la reproduction présente et future vers une augmentation de l'entretien personnel au détriment de l'investissement reproductif.

Mots-clés : chevauchement de la mue et de la reproduction, compromis d'histoire de vie, Ficedula hypoleuca, Haemoproteus, HSP, survie locale.

Nomenclature: Cramp, Perrins \& Brooks, 1993.

\footnotetext{
${ }^{1}$ Rec. 2006-02-23; acc. 2006-07-21.

Associate Editor: Marty Leonard.

${ }^{2}$ Author for correspondence.
} 


\section{Introduction}

Life history theory predicts the occurrence of tradeoffs between reproduction and self-maintenance processes (Lessells, 1991; Stearns, 1992). Thus, a physiological trade-off could be expected between reproduction and the annual moult in birds, when both processes coincide in time (Svensson \& Nilsson, 1997). All birds replace worn plumage during a periodic moult (Payne, 1972), resulting in a new set of feathers with a higher efficiency in flight performance and insulation (Ginn \& Melville, 1983). This maintenance process is costly in terms of energy (Dietz, Daan \& Masman, 1992; Klaassen, 1995; Murphy, 1996) and may raise daily energy expenditure to a level almost as high as that experienced while breeding (Lindström, Visser, \& Daan, 1993). Thus, moult and breeding are normally separated in time to minimize energetic costs (Jenni \& Winkler, 1994; Langston \& Hillgarth, 1995) or, alternatively, to avoid predation risks (Slagsvold \& Dale, 1996).

However, moult-breeding overlaps have been reported in many resident and migratory species (Ojanen \& Orell, 1982; Slagsvold \& Lifjeld, 1989; Jenni \& Winkler, 1994; Sanz, 1997; Sanz, 1999; Hemborg, Sanz \& Lundberg, 2001; Moreno, 2004). This overlap between moult and reproduction is known to impair reproductive success (Siikamäki, Hovi \& Rätti, 1994; Langston \& Rohwer, 1996; Svensson \& Nilsson, 1997; Hemborg, 1998; Hemborg \& Lundberg, 1998; Hemborg, Lundberg \& Siikamäki, 1998).

In long-distance migrants it may be adaptive to overlap to some degree reproduction and moult, as there is a time constraint to complete these two resource-demanding activities before migration to winter quarters (Hemborg, 1999). Early moulting may imply adverse consequences for the current breeding attempt (Siikamäki, Hovi \& Rätti, 1994; Hemborg, 1998; Hemborg \& Lundberg, 1998; Hemborg, Lundberg \& Siikamäki, 1998) but may allow earlier moult completion or a slower moult process in a context of high food availability. In addition, early completion of plumage moult may guarantee an earlier onset of migration, with its consequent advantages for survival during migration (Järvinen, 1983; Berthold, 1993; Cuadrado \& Hasselquist, 1994; Sanz \& Moreno, 2000) and possibly for territory occupancy at winter quarters (Salewski, Bairlein \& Leisler, 2002). A slower moult process may enhance resulting plumage quality (Holmgren \& Hedenström, 1995; Dawson et al., 2000) with higher insulating capacity (Nilsson \& Svensson, 1996). Thus, early moulting may be the expression of a shift in the trade-off between present and future reproduction towards enhanced self-maintenance and post-reproductive survival. However, we are aware of no study reporting that a moult-breeding overlap results in benefits in terms of health, stress, condition, and adult survival.

Haemoparasites may directly affect allocation of resources to reproduction or to self-maintenance activities (Møller, 1997; Sanz et al., 2001). Thus, blood parasites may reduce the reproductive value of a breeding attempt. To our knowledge, hematozoan infections have not been studied as a proximate factor affecting moult patterns in wild birds during reproduction. Physiological stress as measured through heat shock proteins in blood (Merino et al.,
1998; Moreno et al., 2002; Tomás et al., 2005) may also be involved when costly processes such as moult and reproduction coincide in time.

In this study on a Spanish population of pied flycatchers, Ficedula hypoleuca, we investigated the occurrence of moult-breeding overlap in females throughout 6 breeding seasons. We specifically focused on females, as they may suffer larger fitness costs than males from moult-breeding overlaps (Hemborg, 1998). Also, male breeding investment may vary in relation to parentage in the brood, a normally uncontrolled factor (Lifjeld et al., 1997; Lubjuhn et al., 2000). In addition, pied flycatcher females can be more easily captured at the nest than males, so female reproductive output and local survival can be more accurately estimated. Our first objective was to study whether female condition, haemoparasite prevalence, and physiological stress level (measured as the level of the stress protein HSP60) were associated with the likelihood of replacing the plumage while still breeding. Another objective was to detect potential associations of moult status with female survival and reproductive success. Finally, we checked if there was individual consistency in moult phenology in a small set of females captured in at least 3 of the study years.

\section{Methods}

\section{STUDY SPECIES AND AREA}

The pied flycatcher is a small (12-13 g), migratory, hole-nesting passerine of European woodlands (Lundberg \& Alatalo, 1992) that is considered a long-distance migrant (Spanish populations make a journey of more than $3000 \mathrm{~km}$ from their winter quarters to their breeding grounds). Adults perform a complete post-nuptial moult before autumn migration (Ginn \& Melville, 1983). A moult-breeding overlap may occur, as reported for this (Sanz, 1997) and other populations of the species (Ojanen \& Orell, 1982; Slagsvold \& Lifjeld, 1989; Siikamäki, Hovi \& Rätti, 1994; Hemborg, Sanz \& Lundberg, 2001). This overlap is more common among young birds (Hemborg, Lundberg \& Siikamäki, 1998; Hemborg, Sanz \& Lundberg, 2001). The overlap between moulting and breeding may differ depending on the latitude of the breeding site (Hemborg, Sanz \& Lundberg, 2001). Despite the assumption that an overlap is more common in populations at northern latitudes, where the breeding season is much shorter (Järvinen, 1983; Sanz, 1997), southern populations may also show a pronounced overlap (Hemborg, Sanz \& Lundberg, 2001; Sanz et al., 2004).

The study was conducted during the breeding seasons of 1999-2004 in a deciduous forest of Pyrenean oak (Quercus pyrenaica) at an elevation of $1200 \mathrm{~m}$ in Valsaín, central Spain $\left(40^{\circ} 48^{\prime} \mathrm{N}, 4^{\circ} 01^{\prime} \mathrm{w}\right)$. Our pied flycatcher population has been the subject of a long-term study since 1991 (Sanz et al., 2003). All birds are individually ringed with numbered aluminium bands (DGCN bands, ringing permit by regional authorities), and their reproductive success and local survival between years is known, as almost all breeding females are captured every year. Female local survival probabilities in this population are quite high, reaching $90 \%$ at 3-4 y of age (Sanz \& Moreno, 2000). As an estimate of female survival, we have used the probability to return to the breeding grounds in the following breed- 
ing season (female local survival). We assume that females that do not breed in the nest-boxes have not returned to the study area. Other methods to estimate survival based in capture-recapture data of the same individual throughout many years (such as MARK) are not suitable for this study, as we have data for only 18 females that were captured in at least 3 study years.

\section{GENERAL METHODS}

None of the birds in this study were included in experiments in the year of measurement or in previous years. On first capture, females were classified as one year of age or older according to Svensson (1984). For some females exact age was known, as they were ringed as nestlings in the study area. We assumed for all recruited adult females that were not raised in the study area a minimum age of $2 \mathrm{y}$ (Sanz \& Moreno, 2000). Egg laying in this population typically begins in late May, and clutch sizes range from 4 to 7 eggs with a mode of 6 eggs.

Data obtained from females were divided into initial (from the onset of incubation to the day after hatching) and late breeding phases (the end of the nestling period) based on how breeding activities differently affect females' energy balance in species with uniparental female incubation and brooding. Initial phases are characterized by a restriction on females' foraging time due to incubation, which induces females to maintain relatively large body reserves through extremely high foraging rates compared with other stages of breeding (Moreno, 1989a,b; Moreno \& Hillström, 1992) and through incubation feeding (Lifjeld \& Slagsvold, 1986). As chicks attain homeothermy, this time limitation disappears. Females thus adjust their time-energy budget accordingly by reducing body reserves in relation with increased time available for foraging until reaching their lowest mass level at the end of the nestling period (Moreno, 1989a,b; Moreno \& Hillström, 1992).

In 1999 and 2002, females were captured at the nest on the day after clutch completion ( $n=34$ and 37, respectively), and in 2004, on the day following hatching $(n=58)$. They were blood-sampled and weighed with a Pesola spring balance (accuracy of $0.25 \mathrm{~g}$; Pesola AG, Baar, Switzerland). Very few females in our population were moulting at these initial stages $(1 \%)$. In all breeding seasons, females (34 females in 1999, 40 in 2000, 27 in 2001, 30 in 2002, 24 in 2003, and 49 in 2004) and males were captured at the nest with nest-box traps when nestlings were 11-12 d (hatching day $=$ day 0 ). They were inspected for primary moult (moulting or not) following Ginn and Melville (1983). We did not use moult score (Ginn \& Melville, 1983) as an index of moult-breeding overlap because we were interested in moult phenology (moulting or not at a certain breeding stage) more than in moult rate. Females and nestlings at this age were weighed, and their tarsus length was measured with a digital caliper to the nearest $0.01 \mathrm{~mm}$. As a measure of body condition we used mass divided by the cube of tarsus length. When nestlings were 10-12 d old, parental provisioning rates were monitored (number of feeding trips performed by both parents). The entrance of the nest-boxes was recorded for $1 \mathrm{~h}$ between 0900 and 1800 with a video camera placed 5-10 $\mathrm{m}$ away from the nest-box. Local recruitment of offspring was recorded as a categorical factor: at least one juvenile in the brood returned to the study area or no juveniles in the brood returned.

\section{HAEMOPARASITE DETECTION}

A blood sample $(80 \mu \mathrm{L})$ was collected from the brachial vein of females in order to detect the presence of the two most common haemoparasites, Trypanosoma and Haemoproteus (Merino \& Potti, 1995; Merino, Potti, \& Fargallo, 1997) at early breeding stages (in 1999, 2002, and 2004) and at a final phase of the reproductive period (in all breeding seasons except 2001). Blood smears were airdried, fixed in absolute ethanol, and stained with Giemsastain $(1 / 10 \mathrm{v} / \mathrm{v})$ for $45 \mathrm{~min}$. One half of each smear was scanned under $200 \times$ magnification in search of the extracellular blood parasite Trypanosoma. In the other half, 50 fields (i.e., a mean of 595 erythrocytes per field) were scanned using $1000 \times$ magnification in search of the intracellular parasite Haemoproteus (Merino, Potti, \& Fargallo, 1997).

\section{DETERMINATION OF PHYSIOLOGICAL STRESS LEVELS}

Physiological stress promotes the synthesis of heat shock proteins (HSPs), a set of molecules that have a very similar structure in all kind of organisms. Their main function is to facilitate protein folding and assembly (Lindquist, 1986; Feder \& Hofmann, 1999). Under a wide variety of environmental stressors, HSP levels are increased to maintain cellular homeostasis (see Sørensen, Kristensen \& Loeschcke, 2003 for a review). Assessment of the HSPmediated response has been shown to be a reliable method for evaluating physiological or environmental stress in wild birds (Merino et al., 1998; Moreno et al., 2002; Tomás et al., 2005). We determined the levels of one of these stress proteins, HSP60 (the number indicates the molecular weight, which is the way to classify stress proteins), as a measure of physiological stress at early breeding stages in 2002 and 2004 and at day 11-12 of the nestling period in 2002-2004. After a blood smear was obtained, the remaining blood sample was centrifuged $(2000 \times g, 5 \mathrm{~min})$ with a portable centrifuge (Labnet, Mini Centrifuge, Cat. $\mathrm{N}^{\circ} 1201-$ $220 \mathrm{~V}$, Woodbridge, New Jersey, USA). Cellular and serum components were separated and frozen on the same day for later analyses of HSP60. We determined the levels of HSP60 from the cellular fraction of blood by means of a Western blot. For details of the protocol, see Moreno et al. (2002) and Tomás et al. (2005).

\section{STATISTICAL ANALYSES AND SAMPLE SIZE}

We used logistic regressions in the GLZ (Generalized Linear Models) module of STATISTICA (version 2001) to associate female moult status (moulting or non-moulting), which was entered as the dependent variable, with physiological and health parameters, entered as explanatory variables. The same module was applied to relate moult status to female local survival (in this case, survival was entered as the dependent variable). We used the GLM (General Linear Models) module, entering breeding parameters as dependent variables, in order to study their association with female moult status. In all the analyses, the following variables were included to correct for their effect: laying date, female age ( 2 categories: 1 y old and older), and year. Laying date 
was standardized across years by subtracting each date from the average laying date of the year. Only in the GLZ performed to detect the effect of HSP60 on female moult status was age not entered as a covariate, as most females were older than $1 \mathrm{y}$ and there was not enough variance in female age for statistical analysis. Non-significant interaction terms between categorical variables were excluded from the models, and thus only significant interactions are presented.

Females captured in more than one year were included only once in the analyses in order to avoid pseudoreplication. The included year was randomly selected among the various capture years. For analyses that included the initial presence/absence of haemoparasites, however, we used a database that included all the data available for those years $(1999,2002$, and 2004), as there were no cases of repeated sampling in the years when initial haemoparasites were quantified. This allowed the use of a larger dataset than if we had used the dataset used for analyses not including parasitization. The analysis performed to investigate individual consistency in moult phenology included 18 females captured in at least 3 of the study years, but these observations on the same females were not included in the rest of the analyses. In sum, we entered the maximum amount of data available for each analysis, which explains the differences in sample sizes among them. In 2004, none of the females included in this study showed infection by trypanosomes either at an initial or a final breeding stage (Table I). We thus excluded this year from the analyses including trypanosomes; consequently, sample sizes are smaller than those shown for Haemoproteus.

\section{Results}

Of 204 females, $29 \%$ were moulting while breeding. Onset of moult (moulting or not) was dependent on calendar date (laying date: $W$ [Wald Stat.] $=19.97, P<0.001$; year: $W=8.16, P=0.15)$, such that a higher proportion of late- than early-breeding birds started moulting while still provisioning nestlings. However, in some years, about half of the females with the earliest laying dates showed a moult-breeding overlap in the nestling stage (for example in $2004,50 \%$ of the earliest females showed a moult-breeding overlap). Therefore, other factors apart from breeding date may have influenced the onset of moult in this population. When correcting for laying date and year, female age was not associated with moult status (age: $W=1.92$, $P=0.17$; laying date: $W=18.11, P<0.001$; year: $W=6.97$, $P=0.22$ ), indicating that it was laying date and not female age that mainly influenced the onset of moult.

The moult status of the 18 females captured in at least 3 years was not repeatable $(W=2.73, P=0.99, n=18)$, which suggests that there was no individual consistency in moult phenology. In this GLZ analysis, moult status was entered as the dependent variable and individual as a categorical factor. We were unable to correct for year or female age in this analysis due to the small sample size available.

Female moult status (moulting or not) was positively associated with that of their mate $\left(\chi^{2}=10.21, P=0.001\right)$. This positive association is a consequence of breeding date (early breeding means that adults do not moult while feed- ing nestlings). As we had already controlled for breeding date, we did not include male moult status in the analyses.

\section{HAEMOPARASITES}

The initial presence/absence of Haemoproteus infection was associated with female moult status (Figure 1, Table II), such that the proportion of infected females at an initial breeding stage was higher among moulting females compared with non-moulting ones. At the end of the nestling period, the prevalence of Haemoproteus did not differ according to moult status (Table II). The prevalence of Trypanosoma did not differ according to moult status either at an initial or at a final breeding stage (Table II). In order to check if moulting females were able to cope better with Haemoproteus infection throughout the season compared with non-moulting ones, we performed a Chi-square analysis of the proportion of moulting and non-moulting initially parasitized females that were or were not parasitized at the end, and there was no significant difference $\left(\chi^{2}=0.004\right.$, $P=0.95)$. Thus, moulting females did not differ in their ability to fight Haemoproteus infection compared with nonmoulting ones.

\section{PHYSIOLOGICAL STRESS}

Female moult status was not related to initial HSP60 levels (Table II). However, moulting females had lower HSP60 levels at the end of the nestling period compared with non-moulting ones (Table II; mean absorbance levels \pm SE: $4386 \pm 691.4$ and $6207 \pm 538.9, n=28$ and

TABLE I. Prevalences in different years of the two most common blood parasites (Trypanosoma and Haemoproteus) found in pied flycatcher females in the study population at initial and final breeding stages. Values between parentheses are sample sizes.

\begin{tabular}{lcrcr}
\hline \hline & \multicolumn{2}{c}{ Trypanosoma } & \multicolumn{2}{c}{ Haemoproteus } \\
Year & Initial & \multicolumn{1}{c}{ Final } & Initial & \multicolumn{1}{c}{ Final } \\
\hline 1999 & $6.3(34)$ & $9.7(34)$ & $30.8(34)$ & $6.3(34)$ \\
2000 & & $73.3(26)$ & & $18.2(26)$ \\
2002 & $60.9(37)$ & $50.0(30)$ & $60.9(37)$ & $36.4(30)$ \\
2003 & & $22.2(22)$ & & $22.2(22)$ \\
2004 & $0(52)$ & $0(37)$ & $26.8(52)$ & $37.0(37)$ \\
\hline \hline
\end{tabular}

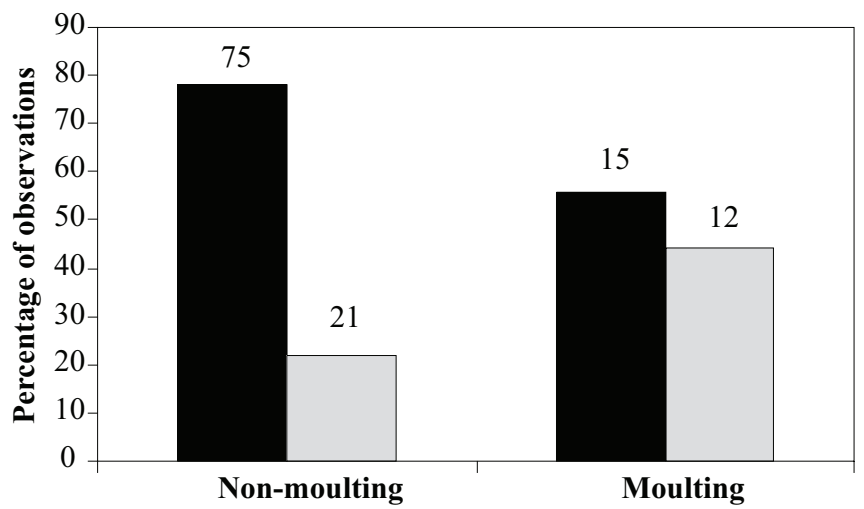

FiguRE 1. Percentage of females infected or not by Haemoproteus blood parasites according to moult status. White bars represent females infected by Haemoproteus at initial breeding stages and black bars represent uninfected females. Sample sizes are shown on top of the bars. 
TABLE II . GLZ analyses with moult status as the dependent variable in relation to the presence/absence of haemoparasites, stress (HSP60), and condition at initial and final breeding stages, correcting for age, laying date, and year. Figures in bold are statistically significant.

\begin{tabular}{|c|c|c|c|c|c|c|c|c|c|}
\hline \multirow[b]{2}{*}{ Physiological parameters } & \multicolumn{2}{|c|}{ Moult status } & \multicolumn{2}{|c|}{ Age } & \multicolumn{2}{|c|}{ Laying date } & \multicolumn{3}{|c|}{ Year } \\
\hline & $W$ & $P$ & $W$ & $P$ & $W$ & $P$ & $W$ & $P$ & $n$ \\
\hline Initial Haemoproteus & 4.97 & 0.026 & 0.51 & 0.48 & 1.09 & 0.3 & 6.4 & 0.04 & 123 \\
\hline Final Haemoproteus & 0.01 & 0.93 & 1.55 & 0.21 & 0.62 & 0.43 & 4.23 & 0.38 & 149 \\
\hline Initial Trypanosoma & 0.84 & 0.36 & 0.05 & 0.83 & 3.46 & 0.063 & 3.92 & 0.048 & 71 \\
\hline Final Trypanosoma & 1.69 & 0.19 & 1.28 & 0.26 & 1.21 & 0.27 & 3.44 & 0.33 & 112 \\
\hline Initial HSP60 & 0.59 & 0.44 & - & - & 2.96 & 0.085 & 0.83 & 0.36 & 69 \\
\hline Final HSP60 & 6.91 & 0.009 & - & - & 5.52 & 0.019 & 4.83 & 0.089 & 90 \\
\hline Initial condition & 2.02 & 0.16 & 0.36 & 0.55 & 3.29 & 0.07 & 7.3 & 0.026 & 97 \\
\hline Final condition & 12.1 & $<0.001$ & 4.93 & 0.026 & 19.4 & $<0.001$ & 11.4 & 0.045 & 197 \\
\hline
\end{tabular}

62, respectively). To explore if there was an association between the initial presence/absence of Haemoproteus and the final HSP60 level, we conducted a GLM analysis with HSP60 level as dependent variable. The initial presence/ absence of Haemoproteus was not associated with the final HSP60 levels $(P=0.17)$.

\section{FEMALE CONDITION}

Moult status was not associated with condition at initial breeding stages (Table II). However, at the end of the nestling period, moulting females were in better condition compared with non-moulting ones (Figure 2, Table II). To explore if there was an association between the initial presence/absence of Haemoproteus and final condition, we conducted a GLM analysis with condition as dependent variable. We found an interaction between the presence/absence of Haemoproteus and moult status affecting final condition, such that infected females with a moultbreeding overlap were in better condition at the end of the season than non-moulting ones (Figure 2; moult status: $F_{1,110}=5.16, P=0.025$; presence/absence of Haemoproteus: $F_{1,110}=0.33, P=0.57$; interaction moult status $\times$ initial presence/absence of Haemoproteus: $F_{1,110}=4.70, P=0.032$; age: $F_{1,110}=1.52, P=0.22$; laying date: $F_{1,110}=4.92$, $P=0.029$; year: $F_{1,110}=1.12, P=0.33$ ).

\section{FEMALE LOCAL SURVIVAL}

Independently of moult status we found no effect of the initial presence/absence of Haemoproteus infection on female local survival (all $P>0.15$ ), and it was thus excluded from the model in order to analyze the largest sample size available. A higher proportion of moulting females returned to the breeding grounds in the following breeding season compared with non-moulting ones (Figure 3; female moult status: $W=6.79, P=0.009$; age: $W=0.65, P=0.42$; laying date: $W=4.88, P=0.027$; year: $W=4.49, P=0.48$; $n=203$ ). Also, females that bred earlier enjoyed a higher survival probability.

\section{BREEDING VARIABLES}

Clutch size, nestling condition, and fledging success (i.e., number of young fledged/number of hatchlings) were not associated with moult status (Table III). The local recruitment of offspring was not associated with moult status either (all $P>0.1$ ). However, moulting females showed lower absolute numbers of hatchlings and fledglings and reduced hatching success (i.e., number of hatchlings/clutch

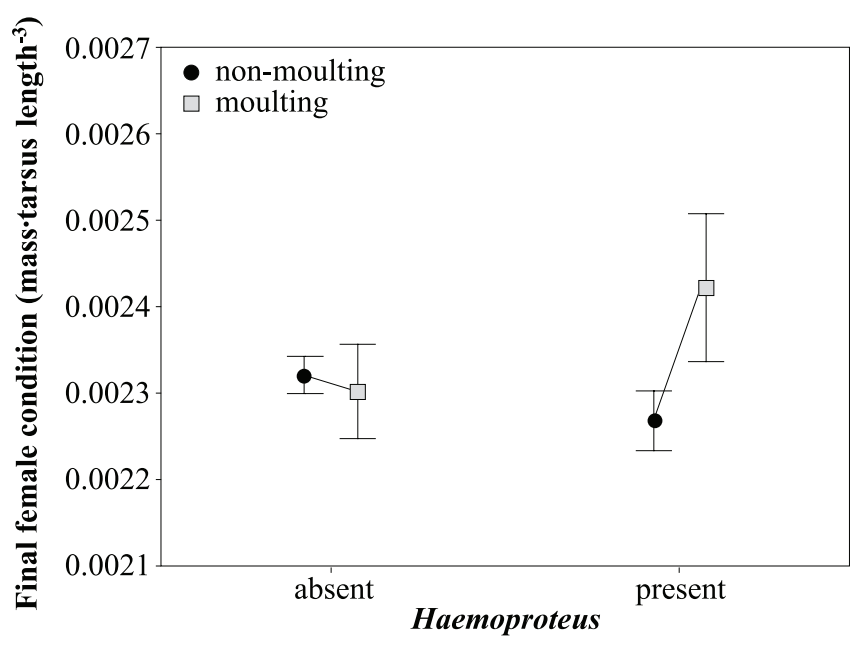

FIGURE 2 Interaction between moult status and the presence/absence of Haemoproteus on initial female condition (mass tarsus length ${ }^{-3}$ ). Bars are means $\pm \mathrm{SE}$.

size) (Table III). Breeding success (i.e., number of young fledged/clutch size) was marginally associated with moult status, with moulting females showing a tendency towards a lower breeding success (Table III). The mean number of hatchlings raised by moulting females was 4.5 versus 5.20 for females without a moult-breeding overlap. Female provisioning rate was not associated with female moult status after correcting for brood size on day 10-12 of nestling age (Table III). The provisioning rates of mates were positively associated $(r=0.28, P=0.001)$. The initial prevalence of Haemoproteus was not associated with any of the breeding output parameters (all $P>0.1$ ).

\section{Discussion}

The proportion of females showing a moult-breeding overlap $(30 \%)$ was in part constituted by early breeding individuals in some years (about half of the females with the earliest breeding dates in some years), indicating that a time constraint before migration was not the only factor inducing moult. Also, age was not significant if laying date and year were taken into account. In addition, females captured in successive years did not always show the same moult phenology, which suggests that the onset of moult is phenotypically plastic. Thus, proximate causes other than age, the timing of breeding, and genetic influence may be also modulating the timing of moult initiation in this population. 
The proportion of infected females at an initial breeding stage was higher among females with a moult-breeding overlap compared with females with no overlap. Though females with a moult-breeding overlap did not differ in stress levels at initial stages, at the end of the nestling period they showed lower stress levels and enjoyed a better condition compared with non-moulting females. Moreover, we found that they enjoyed a better condition if they moulted while still breeding. This indicates that females with a moult-breeding overlap may have shifted investment towards self-maintenance processes during reproduction. Previous studies have reported that an experimental immune activation during the breeding period resulted in a delay of the onset of moult (Ilmonen, Taarna \& Hasselquist, 2000; Sanz et al., 2004), which seems to contradict our evidence that a higher proportion of females infected by haemoparasites advanced moult initiation. However, experimental induction of a short-term immune response at the time of moult initiation in those studies (Ilmonen, Taarna \& Hasselquist, 2000; Sanz et al., 2004) may not have led to the resource reallocations sustained by chronically infected females that did not have to mount a sudden and strong immune response at that stage (Wakelin, 1996). Alternatively, moult may entail previous hormonal changes or alterations of the immune function that could increase susceptibility to haemoparasite infections. This could explain why in our study a higher proportion of females with a moult-breeding overlap were initially infected by Haemoproteus.

A shift in priorities from reproduction to self-maintenance was also shown by the lower absolute number of hatchlings and fledglings raised by moulting females as a consequence of their reduced hatching success. Also, breeding success was marginally significantly associated with moult status. Our correlative results are in accordance with a previous experimental study in the same species: Hemborg and Lundberg (1998) directly induced moult by removing the two innermost primaries of both wings in adults and found that the number of nestlings recruited in the year after manipulation was lower for the group with a moult-breeding overlap. Other studies have shown that moult-breeding overlaps have deleterious consequences for reproductive success (Siikamäki, Hovi \& Rätti, 1994; Svenson \& Nilsson, 1997; Hemborg, 1998). This could be due to impaired flight performance (Haukioja, 1971; Tucker, 1991; Swaddle \& Witter, 1997) or to a shift in the trade-off between investment in present and future reproduction. This shift may depend on the reproductive value of the present breeding attempt. Non-experienced or low-quality females, for instance young and late individuals or those in a poor condition or health status (e.g., infected by blood parasites or more stressed due to impaired health or other causes), might benefit from an advanced moult process if it enhances the likelihood of returning to the breeding grounds and performing future breeding attempts of a higher reproductive value. The shift in life history proposed raises the question of why moulting females did not lay smaller clutches. It is possible that the physiological processes leading to the initiation of moult may begin after egg laying has ceased. Also, it may be non-adaptive to reduce clutch size at so early a stage, when conditions for breeding and mate help are still unknown.

However, in our study, nestling condition, fledging success (i.e., the number of young fledged/number of hatchlings), and offspring local recruitment did not differ according to moult status. Also, female provisioning rate was not affected by moult status. Therefore, the proposed shift in female investment only affected the incubation phase, when females were not yet moulting, and not the nestling stage. A likely explanation is that moulting females had to care for one chick less than non-moulting ones (a 14\% reduction

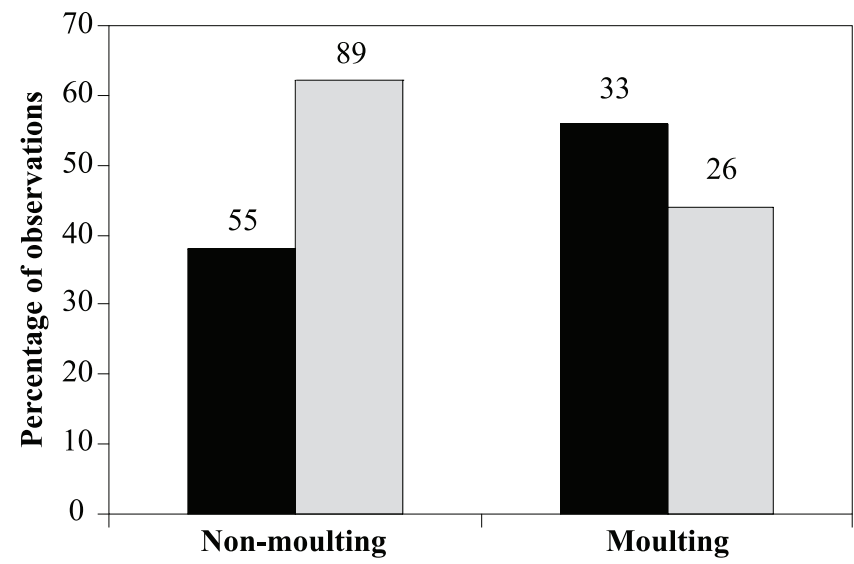

Figure 3. Percentage of females returning or not the following breeding season according to moult status. Black bars represent females that returned to the breeding grounds in the following breeding season, and grey bars represent females that did not return. Sample sizes are shown on top of the bars.

TABLE III. GLM analyses with reproductive parameters as dependent variables in relation to moult status, correcting for age (one year old or older), laying date, and year. Figures in bold are statistically significant.

\begin{tabular}{|c|c|c|c|c|c|c|c|c|c|}
\hline \multirow[b]{2}{*}{ Reproductive parameters } & \multicolumn{2}{|c|}{ Moult status } & \multicolumn{2}{|c|}{ Age } & \multicolumn{2}{|c|}{ Laying date } & \multicolumn{2}{|c|}{ Year } & \multirow[b]{2}{*}{$n$} \\
\hline & $F$ & $P$ & $F$ & $P$ & $F$ & $P$ & $F$ & $P$ & \\
\hline Clutch size & 1.31 & 0.26 & 0.11 & 0.74 & 37.71 & $<0.001$ & 3.52 & 0.005 & 204 \\
\hline Hatching success & 8.89 & 0.003 & 0.02 & 0.89 & 0.46 & 0.5 & 0.85 & 0.51 & 202 \\
\hline No. hatchlings & 10.14 & 0.002 & 0.01 & 0.92 & 17.78 & $<0.001$ & 2.22 & 0.053 & 202 \\
\hline Fledging success & 0.003 & 0.97 & 0.27 & 0.61 & 4.59 & 0.034 & 3.75 & 0.003 & 177 \\
\hline No. fledglings & 4.89 & 0.028 & 0.21 & 0.65 & 13.02 & $<0.001$ & 3.62 & 0.004 & 177 \\
\hline Breeding success & 3.01 & 0.085 & 0.34 & 0.56 & 1.37 & 0.24 & 2.36 & 0.042 & 177 \\
\hline Nestling condition & 0.17 & 0.68 & 0.09 & 0.77 & 0.04 & 0.83 & 8.01 & $<0.001$ & 179 \\
\hline Female provisioning rate 1 & 0.51 & 0.49 & 1.1 & 0.3 & 11.37 & 0.001 & 7.93 & $<0.001$ & 134 \\
\hline
\end{tabular}

${ }^{1}$ In this GLM, the effect of brood size was corrected for: $F_{1,124}=21.22, \boldsymbol{P}<\mathbf{0 . 0 0 1}$. 
in demand). The drastic reduction in hatching success thus precluded detection of any significant effects on fledging success. The provisioning rates of mates were positively associated, which indicates that there is no evidence for a trade-off between sexes. Also, male moult status was positively associated with that of females, which supports no existence of a trade-off according to moult status. An alternative explanation for the results found about breeding parameters would be that females that, for unknown reasons, had reduced hatching success benefited from starting to moult earlier, as they could allocate more resources to selfmaintenance. In this case, it might not be a strategic choice to shift the trade-off between current and future reproduction but merely making the best of a bad job. Although we cannot determine the causal relationship between moult and reduced hatching success, it is not obvious that the physiological processes leading to moult had not started already at incubation. Moult entails vascularization of the feather follicles, which allows the mobilization of higher hormone levels, oxygen, and nutrients (Payne, 1972). It also affects organ and tissue masses (Murphy, 1996), and therefore the processes leading to moult are presumably not rapid or instantaneous and could have already started during incubation. Indeed, there is evidence in the study population that females with a moult-breeding overlap show a lower predisposition to invest at an early stage of reproduction, as a higher proportion of these females reduce clutch size during incubation by ejecting eggs outside the nest rim compared with females without a moult-breeding overlap (Lobato et al., 2006). Only a physiological study unravelling the timing of the physiological processes leading to moult in relation with actual feather shedding will be able to separate both possibilities.

We found that a higher proportion of moulting females returned to the breeding grounds in the following breeding season than non-moulting ones. Thus, bringing forward the onset of moult and accepting some moult-breeding overlap, though costly in terms of reproductive output, might be advantageous for females, especially infected ones. As moult must be completed in any case before migration, females might benefit if they start it as soon as possible, when for instance food availability is still high, at the expense of reduced reproductive output. Advanced moult may also imply advantages in terms of earlier migration (Järvinen, 1983) or improved plumage quality (Dawson et al., 2000) and may avoid the negative fitness consequences of migrating with an incomplete set of new feathers (Jenni \& Winkler, 1994; Pérez-Tris et al., 2001). As the moult schedule is constrained by the timing of migration (Kjellén, 1994; Holmgren \& Hedenström, 1995), the shorter length of the migration route in southern populations may favour a slower moult process and imply better chances of survival during migration (Järvinen, 1983; Berthold, 1993). Thus, the impacts of early moulting on adult survival prospects may differ between populations (Sanz, 2001). While individuals in populations with reduced adult survival may not be able to benefit from the presumed advantages of early moulting for migration advancement and plumage quality (Hemborg \& Lundberg, 1998), those experiencing reduced mortality hazards may benefit from an advancement of moult in terms of improved survival. In the first case, the benefits of early moulting may be swamped by the stronger effects of other mortality factors. Southern populations of migratory species in north-temperate areas may in fact survive better due to the shorter migratory route, as expressed by delayed senescence (Sanz \& Moreno, 2000), and could experience fitness benefits from advancing moult processes. Only in populations where advanced moult has beneficial effects on post-reproductive survival prospects would we expect advanced moulting and consequent prolonged moult-breeding overlaps.

That the prevalence of Haemoproteus did not affect breeding parameters and female local survival is consistent with a previous study (Dale, Kruszewicz \& Slagsvold, 1996), in which Haemoproteus infection apparently had no negative effects on the breeding success and survival of male pied flycatchers. However, we cannot conclude that infection did not exert negative effects on female fitness. Chronic haemoparasite infections may mediate reproductive trade-offs, and the fact that a higher proportion of infected females moulted while breeding at the cost of reduced reproductive success supports this possibility.

To conclude, despite the negative consequences in terms of reproductive fitness, females with a moult-breeding overlap enjoyed advantages in terms of improved condition, reduced stress, and higher return rates than females with no overlap. Early moult in females may be the expression of a shift in the life history trade-off between present and future reproduction towards self-maintenance functions favouring post-reproductive survival prospects. Alternatively, females that for unknown reasons have reduced hatching success might benefit from starting to moult earlier, as they may allocate more resources to self-maintenance. Overlapping moult and breeding may be especially important for longdistance migrants, which are time-constrained to replace worn feathers before migration.

\section{Acknowledgements}

The study received financial support from projects CGL200400787/BOS to J. Moreno and BOS2003-05724 to S. Merino (DGI-Ministerio de Educación y Ciencia). We thank T. Calvo and C. Corral for help in the field. We also thank J. Martínez for invaluable advice during lab work and M. Artiles for haemoparasite detection. J. Donés, Director of Centro Montes de Valsaín (Ministerio de Medio Ambiente) authorized our work in the study area. Dirección General del Medio Natural (Junta de Castilla y León) authorized the capture and ringing of birds in the study area. This paper is a contribution from the El Ventorrillo field station. J. Morales and G. Tomás were supported by an FPI grant from MEC and CAM respectively. E. Lobato was supported by an FPU grant from MEC. J. Martínez-de la Puente was supported by an I3P grant from CSIC.

\section{Literature cited}

Berthold, P. (ed.), 1993. Bird Migration: A General Survey. Oxford University Press, Oxford.

Cramp, S., C. M. Perrins \& D. J. Brooks, 1993. The Birds of the Western Palearctic. Volume 7. Oxford University Press, Oxford.

Cuadrado, M. \& D. Hasselquist, 1994. Age-related difference in return rate of willow warblers Phylloscopus trochilus at two breeding sites in Sweden. Ornis Fennica, 71: 137-143. 
Dale, S., A. Kruszewicz \& T. Slagsvold, 1996. Effects of blood parasites on sexual and natural selection in the pied flycatcher. Journal of Zoology, 238: 373-393.

Dawson, A., S. A. Hinsley, P. N. Ferns, R. H. C. Bonser \& L. Eccleston, 2000. Rate of moult affects feather quality: A mechanism linking current reproductive effort to future survival. Proceedings of the Royal Society of London, B, 267: 2093-2098.

Dietz, M. W., S. Daan \& D. Masman, 1992. Energy requirements for molt in the kestrel Falco tinnunculus. Physiological Zoology, 65: 1217-1235.

Feder, M. E. \& G. E. Hofmann, 1999. Heat-shock proteins, molecular chaperones, and the stress response: Evolutionary and ecological physiology. Annual Review of Physiology, 61: 243-282.

Ginn, H. B. \& D. S. Melville (eds.), 1983. Moult in Birds (BTO Guide 19). British Trust of Ornithology, Thetford.

Haukioja, E., 1971. Flightlessness in some moulting passerines in Northern Europe. Ornis Fennica, 48: 101-116.

Hemborg, C., 1998. Sexual differences in the control of postnuptial moult in the pied flycatcher. Animal Behaviour, 56: $1221-1227$.

Hemborg, C., 1999. Annual variation in the timing of breeding and moulting in male and female Pied Flycatchers Ficedula hypoleuca. Ibis, 141: 226-232.

Hemborg, C. \& A. Lundberg, 1998. Costs of overlapping reproduction and moult in passerine birds: An experiment with the pied flycatcher. Behavioral Ecology \& Sociobiology, 43: 19-23.

Hemborg, C., A. Lundberg \& P. Siikamäki, 1998. Trade-off between reproduction and moult: A comparison of three Fennoscandian pied flycatcher populations. Oecologia, 117: 374-380.

Hemborg, C., J. J. Sanz \& A. Lundberg, 2001. Effects of latitude on the trade-off between reproduction and moult: A long-term study with pied flycatcher. Oecologia, 129:206-212.

Holmgren, N. \& A. Hedenstrom, 1995. The scheduling of molt in migratory birds. Evolutionary Ecology, 9: 354-368.

Ilmonen, P., T. Taarna \& D. Hasselquist, 2000. Experimentally activated immune defence in female pied flycatchers results in reduced breeding success. Proceedings of the Royal Society of London, B, 267: 665-670.

Järvinen, A., 1983. Breeding strategies of hole-nesting passerines in Northern Lapland. Annales Zoologici Fennici, 20: 129-149.

Jenni, L. \& R. Winkler (eds.), 1994. Moult and Ageing of European Passerines. Academic Press, London.

Kjellén, N., 1994. Moult in relation to migration in birds: A review. Ornis Svecica, 4: 1-24.

Klaassen, M., 1995. Molt and basal metabolic costs in males of two subspecies of Stonechats: The European Saxicola torquata rubicula and the East African Saxicola torquata axillaris. Oecologia, 104: 424-432.

Langston, N. E. \& N. Hillgarth, 1995. Molt varies with parasites in laysan albatrosses. Proceedings of the Royal Society of London, B, 261: 239-243.

Langston, N. E. \& S. Rohwer, 1996. Molt-breeding tradeoffs in albatrosses: Life history implications for big birds. Oikos, 76: 498-510.

Lessells, C. M., 1991. The evolution of life histories. Pages 32-68 in J. Krebs \& N. B. Davies (eds.). Behavioural Ecology: An Evolutionary Approach. Blackwell Scientific, Oxford.

Lifjeld, J. T. \& T. Slagsvold, 1986. The function of courtship feeding during incubation in the pied flycatcher Ficedula hypoleuca. Animal Behaviour, 34: 1441-1453.
Lifjeld, J. T., T. Slagsvold, S. Dale \& H. Ellegren, 1997. A sexually selected paradox in the pied flycatcher: Attractive males are cuckolded. Auk, 114: 112-115.

Lindquist, S., 1986. The heat-shock response. Annual Review of Biochemistry, 55: 1151-1191.

Lindström, A., G. H. Visser \& S. Daan, 1993. The energetic cost of feather synthesis is proportional to basal metabolic rate. Physiological Zoology, 66: 490-510.

Lobato, E., J. Moreno, S. Merino, J. J. Sanz, E. Arriero, J. Morales, G. Tomás \& J. Martínez-de la Puente, 2006. Maternal clutch reduction in the pied flycatcher: An undescribed clutch size adjustment mechanism. Journal of Avian Biology, 37: 637-641.

Lubjuhn, T., W. Winkel, J. T. Epplen \& J. Brun, 2000. Reproductive success of monogamous and polygynous pied flycatchers (Ficedula hypoleuca). Behavioral Ecology \& Sociobiology, 48: 12-17.

Lundberg, A. \& R. V. Alatalo, 1992. The Pied Flycatcher. Poyser, London.

Merino, S. \& J. Potti, 1995. High prevalence of hematozoa in nestlings of a passerine species, the Pied Flycatcher (Ficedula hypoleuca). Auk, 112: 1041-1043.

Merino, S., J. Potti \& J. A. Fargallo, 1997. Blood parasites of some passerine birds from central Spain. Journal of Wildlife Diseases, 33: 638-641.

Merino, S., J. Martínez, A. Barbosa, A. P. Møller, F. de Lope, F. Pérez \& F. Rodríguez-Caabeiro, 1998. Increase in a heat-shock protein from blood cells in response of nestling house martins (Delichon urbica) to parasitism: An experimental approach. Oecologia, 116: 343-347.

Møller, A. P., 1997. Parasites and the evolution of host life history. Pages 105-127 in D. Clayton \& J. Moore (eds.). Host-Parasite Evolution: General Principles and Avian Models. Oxford University Press, Oxford.

Moreno, J., 1989a. Body-mass variation in breeding Northern Wheatears: A field experiment with supplementary food. Condor, 91: 178-186.

Moreno, J., 1989b. Strategies of mass change in breeding birds Biological Journal of the Linnean Society, 37: 297-310.

Moreno, J., 2004. Moult-breeding overlap and fecundity limitation in tropical birds: A link with immunity? Ardeola, 51: 471-476.

Moreno, J. \& L. Hillström, 1992. Variation in time and energy budgets of breeding Wheatears. Behaviour, 120: 11-39.

Moreno, J., S. Merino, J. Martínez, J. J. Sanz \& E. Arriero, 2002. Heterophil/lymphocyte ratios and heat-shock protein levels are related to growth in nestling birds. Écoscience, 9: 434-439.

Murphy, M. E., 1996. Energetics and nutrition of molt. Pages 158-198 in C. Carey (ed.). Avian Energetics and Nutritional Ecology. Chapman and Hall, New York, New York.

Nilsson, J. A. \& E. Svensson, 1996. The cost of reproduction: A new link between current reproductive effort and future reproductive success. Proceedings of the Royal Society of London, B, 263: 711-714.

Ojanen, M. \& M. Orell, 1982. Onset of moult among breeding pied flycatchers (Ficedula hypoleuca) in northern Finland. Die Vogelwarte, 31:445-451.

Payne, R. B., 1972. Mechanisms and control of molt. Pages 104 155 in D. S. Farner \& J. R. King (eds.). Avian Biology, Volume 2. Academic Press, New York, New York.

Pérez-Tris, J., J. de la Puente, J. Pinilla \& A. Bermejo, 2001. Body moult and autumn migration in the barn swallow Hirundo rustica: Is there a cost of moulting late? Annales Zoologici Fennici, 38: 139-148. 
Salewski, V., E. Bairlein \& B. Leisler, 2002. Different wintering strategies of two Palearctic migrants in West Africa: A consequence of foraging strategies? Ibis, 144: 85-93.

Sanz, J. J., 1997. Clutch size manipulation in the pied flycatcher: Effects on nestling growth, parental care and moult. Journal of Avian Biology, 28: 157-162.

Sanz, J. J., 1999. Seasonal variation in reproductive success and post-nuptial moult of blue tits in southern Europe: An experimental study. Oecologia, 121: 377-382.

Sanz, J. J., 2001. Latitudinal variation in female local return rate in the philopatric pied flycatcher (Ficedula hypoleuca). Auk, 118: 539-543.

Sanz, J. J. \& J. Moreno, 2000. Delayed senescence in a southern population of the pied flycatcher (Ficedula hypoleuca). Écoscience, 7: 25-31.

Sanz, J. J., E. Arriero, J. Moreno \& S. Merino, 2001. Female hematozoan infection reduces hatching success but not fledging success in pied flycatchers Ficedula hypoleuca. Auk, 118: $750-755$.

Sanz, J. J., J. Potti, J. Moreno, S. Merino \& O. Frías, 2003. Climate change and fitness components of a migratory bird breeding in the Mediterranean region. Global Change Biology, 9: 461-472.

Sanz, J. J., J. Moreno, S. Merino \& G. Tomás, 2004. A trade-off between two resource-demanding functions: Post-nuptial moult and immunity during reproduction in male pied flycatchers. Journal of Animal Ecology, 73: 441-447.

Siikamäki, P., M. Hovi \& O. Rätti, 1994. A trade-off between current reproduction and molt in the pied flycatcher: An experiment. Functional Ecology, 8: 587-593.
Slagsvold, T. \& S. Dale, 1996. Disappearance of female pied flycatchers in relation to breeding stage and experimentally induced molt. Ecology, 77: 461-471.

Slagsvold, T. \& J. T. Lifjeld, 1989. Hatching asynchrony in birds: The hypothesis of sexual conflict over parental investment. American Naturalist, 134: 239-253.

Sørensen, J. G., T. N. Kristensen \& V. Loeschcke, 2003. The evolutionary and ecological role of heat shock proteins. Ecology Letters, 6: 1025-1037.

Stearns, S. C. (ed.), 1992. The Evolution of Life-Histories. Oxford University Press, Oxford.

Svensson, E. \& J. A. Nilsson, 1997. The trade-off between molt and parental care: A sexual conflict in the blue tit? Behavioural Ecology, 8: 92-98.

Svensson, L. (ed.), 1984. Identification Guide to European Passerines. Ugga, Stockholm.

Swaddle, J. P. \& M. S. Witter, 1997. The effects of moult on the flight performance, body mass, and behaviour of European Starlings (Sturnus vulgaris): An experimental approach. Canadian Journal of Zoology, 75: 1135-1146.

Tomás, G., S. Merino, J. Martínez, J. Moreno \& J. J. Sanz, 2005. Stress protein levels and blood parasite infection in blue tits (Parus caeruleus): A medication field experiment. Annales Zoologici Fennici, 42: 45-56.

Tucker, V. A., 1991. The effect of molting on the gliding performance of a Harris' hawk (Parabuteo unicinctus). Auk, 108: $108-113$.

Wakelin, D. (ed.), 1996. Immunity to parasites: How parasitic infections are controlled. Cambridge University Press, Cambridge. 